\title{
THE SELF-MANAGEMENT EXPERIENCE OF SUBJECTS WITH HYPERTENSION - RESULTS FROM A QUALITATIVE STUDY (WARSAW, POLAND)
}

\author{
ANNA MARIA DWORAKOWSKA*, MONIKA ZAWADA, \\ and MAŁGORZATA KOZŁOWSKA-WOJCIECHOWSKA
}

Department of Clinical Pharmacy and Pharmaceutical Care, Medical University of Warsaw, ul. Banacha 1, 02-097 Warsaw, Poland

\begin{abstract}
Background Arterial hypertension is a serious public health problem. In Poland, hypertension is controlled only in about $21 \%$ of patients in the primary care setting. The efficacy of hypertension treatment depends on the selection of appropriate therapy and active patient involvement. The aim of the study was to explore the experiences, beliefs and motivations regarding hypertension and its treatment using the grounded theory. The study was conducted using the semi-structured, face-to-face interviews among the purposive sample. Transcriptions were thematically coded and analyzed using constant comparison. Data saturation was reached. Twenty hypertensive patients (10 women and 10 men) aged 50-59 years participated in the study. Generally, patients feel at risk due to hypertension. As part of self-management, they try to take their medication regularly and modify their lifestyles. The relationship with the health care provider is key to the success of self-management. The study subjects identified many benefits and factors motivating them for self-management. The study revealed also numerous barriers, particularly with reference to implementing lifestyle modifications. Although the study subjects demonstrated overall proactive attitudes, there is a number of barriers to self-management. It is essential to know these barriers and methods to overcome them in order to promote self-management practices.
\end{abstract}

Keywords: health education, patients, hypertension, healthy lifestyle, drug misuse

Hypertension is a global health issue (1). The prevalence of hypertension in Poland is high and increases over time (2). Nearly $1 / 4$ of Polish people are diagnosed with hypertension (3, p. 66), and $21 \%$ take blood pressure-lowering medications longterm. The number of hypertensive patients increases significantly with age, e.g. $31.1 \%$ of Polish people are diagnosed with hypertension within the age group 50-59, whereas the corresponding rate for people aged 60 to 69 years amounts to $46.5 \%$ (3).

Hypertension treatment is life-long and places many demands on the patient $(4,5)$. As part of selfmanagement, a hypertensive patient is obliged to take his/her medication regularly, follow a diet and specific dietary restrictions, quit smoking, exercise regularly, and collaborate with a health care provider $(4,6)$. Self-management requires from the patient such skills as problem-solving, decision making, resource utilization, the formation of a part- nership with a health care provider, taking action, and self-tailoring (7).

On average, only about half of patients with chronic hypertension takes medication as prescribed (8). In an international study, $57.6 \%$ of subjects from Poland self-reported as being non-adherent (9). Patients adhere to lifestyle modifications even less often $(2,10,11)$. Currently, hypertension is controlled in only about $20.7 \%$ of patients $(2,12)$. The control of hypertension in Poland increases with age (13). The number of patients achieving therapeutic goals is steadily increasing, however, it is still unsatisfactory. Further action is needed to improve the diagnosis and effective treatment of hypertension in Poland (2).

Due to the limited number of qualitative studies on hypertension in Poland, the aim of the study was to explore the experiences, beliefs and motivations regarding hypertension and its treatment using the grounded theory (14).

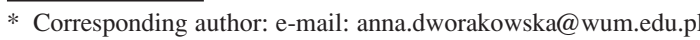




\section{Methods \\ Study design and data collection}

This was a qualitative study (15), conducted using the semi-structured, face-to-face interviews. The study was conducted after receiving approval of the Ethics Committee at the Medical University of Warsaw, Poland, no. AKBE18/14.

A purposive study sample was recruited based on the following criteria: (a) the age of participants (50-59 years of age), and (b) diagnosed with hypertension. As the study proceeded, the theoretical sampling was employed, guided by the consecutive analysis of data. Sampling continued until theoretical saturation occurred (no new data was generated). Patients were enrolled in the study once they had been informed about the study purpose and methods and had signed the informed consent form for participation in the study. No incentives were offered. Interviews were conducted between 31 March and 9 April 2014 at the Department of Hypertension of the Institute of Cardiology in Warsaw, Poland.

The guide asked similar general questions (e.g., Please tell me what comes to your mind when you think about your hypertension? Please tell me about the use of your hypertension medications). Questions referred to specific components of self-management (e.g., medication management, lifestyle modifications, collaboration with a doctor). Questions asked participants evolved depending on consecutive data analysis. Probing questions were used for clarification or to gain greater insight into participants' opinions. Interviews lasted about 30-40 min.

Interviews were recorded and transcribed verbatim. The data analysis process used a grounded theory approach. Two investigators (MZ and AD) independently analyzed data using thematic analysis, with no preconceived categories. The initial codes and categories were generated and revised by the research team. The coding process used a constant comparison of the analysis with subsequent interviews. Data saturation was reached.

The emerging themes fitted to the Health Belief Model constructs, therefore we decided to recode the transcripts and revise the themes to better reflect the Health Belief Model. Both researchers independently re-coded all of the transcripts and identified the representative quotes. The obtained results were discussed by the entire research team until the agreement was reached.

\section{RESULTS}

Ten women and 10 men with hypertension, aged 50-59 years, participated in the study. The mean time from diagnosis was 12.7 years (standard deviation: 7.9, median: 10 years).

Perceived severity of hypertension and susceptibility of possible complications

Nearly all study subjects expressed the belief that hypertension is a serious medical condition that may cause severe consequences. Many patients feared future complications such as stroke, apoplexy, death.

In some cases, the study subjects themselves or a person close to them experienced a sudden increase in blood pressure (BP), which could leave permanent, adverse health outcomes. This experience consolidated their belief that the risk of severe complications of hypertension is real.

One patient was previously diagnosed with hypertension, but he downplayed the importance of treatment until he lost consciousness and was taken to a hospital.

One patient had no sense of disease threat.

\section{Seeking information about hypertension}

Most respondents believe to be well-informed about hypertension and its treatment - this belief is shaped by a long time from diagnosis and the start of treatment, and the fact that information is repeated by several specialists. The most important source of information about hypertension is a doctor.

However, the information provided at the beginning of treatment may turn out to be insufficient: "He told me a bit at the beginning, but I've already forgotten everything." (P6).

Few study subjects sought additional information about the disease and the treatment. The Internet was the most common source of this data; less frequently, it was obtained from articles, leaflets as well as other people.

Beliefs and experiences with hypertension selfmanagement

\section{Self-management}

Most study subjects realize that hypertension is an incurable disease; BP may be lowered with medication and BP self-monitoring, however, the treatment is generally life-long.

Hypertension is believed to be asymptomatic, however, most study subjects observe symptoms of increased BP, which help them in self-management.

\section{Medication adherence}

Nearly all study participants believe that regular intake of medicines is necessary. Some patients emphasize that they always have a supply of med- 
ication and they take them every day at the same time.

Among factors enhancing medication adherence, patients mention confidence in the doctors' authority: "I try to take medication as prescribed, I don't skip any doses, I don't miss any days, or I don't change these medicines myself; I do it as my doctor told me to." (P10).

Some patients admit they forget to take their medication. In general, this happens occasionally: „Nowadays I actually take my pills regularly, which wasn't always the case. I took them once a week or once every few days because I forgot. Now I remember pretty regularly.” (P17).

Gaps in medication intake may result from using up the supply. In this situation, some patients make arrangements to obtain medication in a different way. One of the patients borrows medicines from her friend when she runs short of her supply.

\section{Lifestyle modifications}

Patients are often aware that lifestyle modifications have a positive impact on BP, although they rarely implement these modifications in real life. A hope to discontinue medication in the future motivates one patient to implement lifestyle modifications: "Now, this year, because I think I will be able to stop taking medication, I follow a weight loss program. I lost $17 \mathrm{~kg}$ within 3 months." (P2).

Over half of the study subjects fail to implement any modifications in their diet or physical activity. The reasons which prevent the patients from implementing lifestyle modifications include their bothersome nature and a lack of strong will and involvement, as well as dependence on a close person, most often - the spouse: "I started to exercise, but because of my backbone problems, I stopped. I am only just starting a diet, but I' $m$ having some difficulty. My wife prevents me from following this diet." (P20).

For one patient, her job is a barrier to using a diet. Another patient does not use a diet, because she has recently given up smoking. Some subjects were not aware they should use a diet or exercise because of their hypertension. Some patients comply with some dietary restrictions due to concomitant medical conditions.

Not everyone complies with the requirement to limit alcohol consumption and quit smoking, despite being aware of their negative impact: "I used to smoke for over a decade. When I started my treatment here, I quit smoking. I didn't smoke a cigarette for 4 years, but now I have started again. I smoke occasionally." (P12).

\section{BP self-monitoring}

Most of the study subjects have a BP diary where they record self-measured BP values, although some patients take measurements only when they feel worse.

Some patients occasionally adjust the dose of their medication on their own, depending on the BP values: "I tried to measure my blood pressure and take medication accordingly, but this is not the way to do it. Medication should be taken regularly." (P16).

\section{Collaboration with the doctor}

Active patient involvement in treatment and cooperation with a doctor is especially important with long-term treatment: "If you've been on treatment for a long time, it becomes different than normal treatment; it's more like cooperation with the doctor; after some time, it starts to look differently. Because the patient knows best what happens to him, how he reacts to different things." (P10).

Each study subject has a regular doctor or group of doctors who treat his/her hypertension. It is most often a cardiologist and a family doctor. Patients perceive the advantage of visiting one doctor only: "I try to visit the same doctor because this doctor knows more or less my case." (P10).

Overall, patients like their doctors and trust them, they appreciate their experience and value the possibility to contact them in emergency, outside their scheduled appointments.

Dissatisfaction with doctors was related to shortening patient visits while taking the time for private conversations with other patients or not receiving exhaustive information about disease and treatment.

Based on some interviews, it appears that a doctor informed a patient about the disease and the treatment at the beginning of their collaboration, but the current visits consist only of a medical exam and writing a prescription.

Patients appreciate when a doctor answers their questions, using a comprehensive language.

\section{Follow-up visits}

Overall, the study participants regularly attend their medical appointments. Some patients do not make an appointment with the doctor in advance, but only when they have no or very little medication left.

The identified study participants' beliefs with regard to hypertension, therapy and doctors can be divided into positive and negative (Table 1). Study participants declared behavior models that can be 
described as proactive (consistent with the self-management concept) or reactive (Table 2).

\section{DISCUSSION}

Overall, the study subjects had a sense of disease threat, which was shaped both by a belief that hypertension is a serious disease and a sentiment of personal susceptibility to real-life risk of adverse outcomes of uncontrolled hypertension. Seeking information helped to improve self-management. A relationship with the doctor seems to be essential for successful therapy. Less frequently, the study participants sought information from other sources. The study subjects were proactively involved in hypertension self-management, which was reflected by their compliance with medical appointments,

Table 1. Summary of positive and negative beliefs of study subjects.

\begin{tabular}{|c|c|c|}
\hline & \multicolumn{2}{|c|}{ Beliefs } \\
\hline & Positive & Negative \\
\hline Disease & $\begin{array}{l}\text { Hypertension is a serious, life-threatening } \\
\text { disease which requires treatment }\end{array}$ & $\begin{array}{l}\text { Patient is not aware that hypertension is a serious } \\
\text { disease; neglects treatment or takes medication only in } \\
\text { response to worsening of symptoms }\end{array}$ \\
\hline Information & $\begin{array}{l}\text { Patient feels that he/she needs to broaden } \\
\text { his/her knowledge about hypertension }\end{array}$ & $\begin{array}{l}\text { Patient feels that he/she does not need additional } \\
\text { information }\end{array}$ \\
\hline Medications & Confidence in prescribed medical treatment & Concerns about the safety of medical treatment \\
\hline \multirow[t]{2}{*}{ Lifestyle } & $\begin{array}{l}\text { Patient knows and feels that he/she should } \\
\text { lead a healthy lifestyle }\end{array}$ & $\begin{array}{l}\text { No awareness that lifestyle affects the disease and the } \\
\text { efficacy of treatment }\end{array}$ \\
\hline & & Ignoring lifestyle modifications \\
\hline \multirow{3}{*}{ Doctor } & Confidence in the doctor & Limited confidence in the doctor \\
\hline & Appreciating the doctor's qualifications & Feeling that the doctor neglects the patient \\
\hline & Patient feels well-informed & $\begin{array}{l}\text { Feeling that the doctor fails to provide adequate } \\
\text { information }\end{array}$ \\
\hline
\end{tabular}

Table 2. Summary of proactive and reactive behaviors identified among the study subjects.

\begin{tabular}{|c|c|c|}
\hline & \multicolumn{2}{|c|}{ Behaviors } \\
\hline & Proactive & Reactive \\
\hline \multirow[t]{2}{*}{ Information } & Patient has questions and expects answers & $\begin{array}{l}\text { Patient seeks additional information only when faced } \\
\text { with a problem or does not seek any further } \\
\text { information about the disease and treatment }\end{array}$ \\
\hline & $\begin{array}{l}\text { Seeking information from the doctor and from } \\
\text { other sources: the Internet, periodicals, leaflets }\end{array}$ & \\
\hline \multirow[t]{2}{*}{ Visits } & Regular visits & $\begin{array}{l}\text { Patient makes an appointment only when the } \\
\text { medication supply has been used up }\end{array}$ \\
\hline & Patient makes an appointment in advance & \\
\hline \multirow{2}{*}{$\begin{array}{l}\text { Adherence to } \\
\text { medications }\end{array}$} & $\begin{array}{l}\text { Prescriptions (re)filled on an ongoing basis; } \\
\text { a sufficient supply of medication }\end{array}$ & $\begin{array}{l}\text { Patient does not always have medication; } \\
\text { borrowing medication }\end{array}$ \\
\hline & Regular medicine intake, the same time of day & $\begin{array}{l}\text { Patient forgets to take medication } \\
\text { Patient attempts to make dose adjustments on } \\
\text { his/her own, depending on blood pressure values }\end{array}$ \\
\hline \multirow{5}{*}{$\begin{array}{l}\text { Adherence to } \\
\text { lifestyle } \\
\text { modifications }\end{array}$} & Regular physical activity & Irregular or no physical activity \\
\hline & Following a diet & $\begin{array}{l}\text { Selective compliance or non-compliance with } \\
\text { dietary restrictions }\end{array}$ \\
\hline & Limiting alcohol consumption & Uncontrolled alcohol consumption \\
\hline & Quitting smoking & Smoking \\
\hline & Blood pressure self-monitoring & Irregular measurements or no self-monitoring \\
\hline
\end{tabular}


declared adherence to treatment recommendations, implementation of lifestyle modifications, BP selfmonitoring, and active response to alarming symptoms.

This study confirms a supposition that illness perceptions, including lack of subjective sense of disease, awareness of long-term treatment and possible consequences of untreated hypertension $(6,9$, 16), are an important barrier to self-management. Although hypertension is considered asymptomatic, the study subjects enumerated subjective symptoms experienced with changes in $\mathrm{BP}(6,17)$ which motivated them to more careful self-monitoring.

The study subjects have a regular doctor and perceive the advantage of visiting only one doctor, who knows them and their medical history. Patients value cordiality and qualifications in a doctor, which may have a positive influence on their compliance with the doctor's instructions $(18,19)$. A negative attitude towards a doctor, which was demonstrated by one study subject, was associated with a sentiment that the doctor neglected the patient by reducing the time of his visit for the benefit of private conversations with other patients. According to Swenna et al., the patient's sense of being taken care of by the doctor, depends on whether the health professional gives the patient his/her undivided attention and has time for the patient (20).

It seems that in Poland the patient-doctor relationship is crucial to the effective management of hypertension. However, limitations of medical encounters contribute to the fact that patients do not receive the full support they need. Therefore, there is a need for inter-professional collaboration between health care specialists (21) and greater involvement of nurses and pharmacists in the longer-term management of hypertension (6). It is worth mentioning that the $2018 \mathrm{ESC} / \mathrm{ESH}$ Guidelines for the Management of Arterial Hypertension (5) (in contrast to the current recommendations of the Polish Society of Hypertension (4)) highlight the important role of nurses and pharmacists in the education, support, and follow-up of treated hypertensive patients to improve BP control (6). While the nurse-led interventions are focused mainly on BP education, self-monitoring and lifestyle advice (22), the pharmacist-led interventions are significantly extended by medication management counseling $(6,23,24)$. Pharmacists are in the ideal position to ensure rational use of medications, however, their role in the health care system of Poland is underutilized. Further effort is needed to involve pharmacists in patient care in Poland. Currently, it is not clear which interventions and/or which elements of pharmacists' interventions are the most effective in managing hypertension (23). The development of pharmacist-led intervention should include the maintenance of patient results over time (24).

Understanding the disease and its treatment is of crucial importance for successful self-management and involvement in the treatment process. Some study patients pointed out that their doctor provided them with information about hypertension at the beginning of treatment, whereas at subsequent visits, the doctor only performed a medical exam and wrote a prescription (25). Although patients feel well-informed, it is necessary to check what the patient knows and remembers $(19,26)$, as well as to motivate him/her to use treatment on a regular basis and inform him/her about the course of the disease, the medication used and the recommendations given $(18,19)$. The study also confirms that information itself is not enough for the patient to obtain selfmanagement competencies (6) - the patient must acquire a sense of shared responsibility and disease control.

In general, the study subjects declare they take their medication regularly, although the studies show that among Polish patients treated for hypertension, medication adherence is unsatisfactory (9). In this study, medication non-adherence consisted of forgetting to take the medication or having no medication (using up the whole supply). Borrowing medication from others and making an appointment with the doctor only when the patient has no or very little medication left is an alarming phenomenon (27). However, in accordance with current legal changes, access to the continuation of medical prescriptions has been facilitated and the competence of pharmacists in the field of prescription has been expanded (28).

In order to evaluate the efficacy of treatment, the study subjects generally monitor their BP (29), which is usually correlated with better medication adherence (30). This research has shown that many patients took the measurements irregularly, depending on the perceived need or necessity (31). The observed BP values may trigger greater attention to therapy; they may motivate medication and/or lifestyle adherence $(30,31)$ or - as was the case with one patient in our study - self-monitoring may lead to unwarranted self-adjustments of medication doses.

Implementing lifestyle modifications, such as salt restriction, increased physical activity and reduction in body weight, show much room for improvement, as they are more bothersome for the 
patient and require greater involvement and effort (32).

It is important to tailor self-management interventions to preferences, capabilities and daily activities of patients. Some patients may benefit from the use of smartphone apps supporting hypertension self-management (33). However, there is limited data on the effectiveness and usability of most of the available apps.

\section{CONCLUSION}

As emphasized by one study subject, hypertensive patients "know best what happens to them", therefore they should be actively involved in their treatment. This study offers a qualitative insight into the experience, beliefs and motivations of patients with regard to hypertension treatment. Promoting self-management is an important method of patient empowerment. An important link supporting selfmanagement is the doctor and his/her relationship with the patient. Doctors should attach more importance to educating patients and implementing interventions intended to improve patient competencies in managing hypertension. Although the study subjects demonstrated overall proactive behaviors, there is a number of barriers to self-management. It is essential to know these barriers and methods to overcome them in order to promote self-management practices.

\section{Funding}

No special funding was obtained.

\section{Conflict of interest}

The authors declare no conflict of interest.

\section{REFERENCES}

1. Mills K.T., Bundy J.D., Kelly T.N.: Circulation 134, 441 (2016).

2. Niklas A, Flotyńska A, Puch-Walczak A., Polakowska M., Topór-Madry R., et al.: Arch. Med. Sci. 14, 951 (2018).

3. Piekarzewska M., Wieczorkowski R., Zajenkowska-Kozłowska A.: Health status of population in Poland in 2014. Central Statistical Office, Warszawa 2016.

4. Tykarski A., Filipiak K.J., Januszewicz A., Litwin M., Narkiewicz K., et al.: Nadciśn. Tętn. Prakt. 5, 1 (2019) (In Polish).
5. Williams B., Mancia G., Spiering W., Rosei E.A., Azizi M., et al.: Eur. Heart J. 39, 3021 (2018).

6. Shahaj O., Denneny D., Schwappach A., Pearce G., Epiphaniou E., et al.: J. Hypertens. 37, 264 (2019).

7. Lorig K.R., Holman H.: Ann. Behav. Med. 26, 1 (2003).

8. Abegaz T.M., Shehab A., Gebreyohannes E.A., Bhagavathula A.S., Elnour A.A.: Medicine (Baltimore). 96, e5641 (2017).

9. Morrison V.L., Holmes E.A., Parveen S., Plumpton C.O., Clyne W. et. al.: Value Health 18, 206 (2015).

10. Braam B., Taler S.J., Rahman M., Fillaus J.A., Greco B.A., et. al.: Clin. J. Am. Soc. Nephrol. 12, 524 (2017).

11. Kwaśniewska M., Pikala M., Bielecki W., Dziankowska-Zaborszczyk E., Rębowska E., et al.: PLoS One 11, e0156766 (2016).

12. Małyszko J., Mastej M., Banach M., Tykarski A., Narkiewicz K., et al.: Eur. Heart J. Suppl. (Suppl D) 21, D97 (2019).

13. Zdrojewski T., Wizner B., Więcek A., Ślusarczyk P., Chudek J., et. al.: J. Hypertens. 34, 532 (2018).

14. Charmaz K.: Constructing grounded theory: a practical guide through qualitative analysis. SAGE Publications Inc., London 2006.

15. Tong A, Sainsbury P, Craig J.: Int. J. Quality Health Care 19, 349 (2007).

16. Jankowska-Polańska B., Chudiak A., Uchmanowicz I., Dudek K., Mazur G., et. al. Patient Prefer. Adherence 11, 363 (2017).

17. Baghianimoghadam M.H., Rahaee Z., Morowatisharifabad M.A., Sharifirad G., Andishmand A., Azadbakht L.: J. Res. Med. Sci. 15, 70 (2010).

18. Jolles E.P., Clark A.M., Braam B.: J. Hypertens. 30, 1500 (2010).

19. Jankowska-Polańska B., Uchmanowicz I., Dudek K., Mazur G.: Patient Prefer. Adherence 10, 2437 (2016).

20. Sweeny K., Shepperd J.A., Han P.K.J.: Health Expect. 16, 230 (2013).

21. Zaugg V., Korb-Savoldelli V., Durieux P., Sabatier B.: Cochrane Database Syst. Rev. 1, CD012042 (2018).

22. Gorina M., Limonero J.T., Álvarez M.: Int. J. Nurs. Stud. 86, 139 (2018).

23. Reeves L., Robinson K., McClelland T., Adedoyin C.A., Broeseker A., Adunlin G.: J. Pharm. Pract. 897190020903573 (2020). 
24. Milosavljevic A., Aspden T., Harrison J.: Int. J. Pharm. Pract. 26, 387 (2018).

25. Windak A., Gryglewska B., Tomasik T., Narkiewicz K., Yaphe J., Grodzicki T.: J. Eval. Clin. Pract. 16, 25 (2010).

26. Hyde Y.M., Kautz D.D.: Rehabil. Nurs. 39, 178 (2014).

27. Chrostowska M., Narkiewicz K.: Curr. Vasc. Pharmacol. 8, 804 (2010).

28. Act of 31 March 2020 amending certain acts in the field of health care system related to the prevention, counteracting and combating of COVID-19 (Journal of Laws of the Republic of Poland of 2020, item 567).
29. Peacock E., Krousel-Wood M.: Med. Clin. North Am. 101, 229 (2017).

30. Fletcher B.R., Hartmann-Boyce J., Hinton L., McManus R.J.: Am. J. Hypertens. 28, 1209 (2015).

31. Bajorek B., Lemay K., Magin P, Roberts C., Krass I., Armour C.: High Blood Press. Cardiovasc. Prev. 24, 149 (2017).

32. Retta T.M., Kwagyn J., Randall O.S.: J. Natl. Med. Assoc. 109, 60 (2017).

33. Alessa T., Hawley M.S., Hock E.S., de Witte L.: JMIR Mhealth Uhealth 7, e13645 (2019).

(C) 2020 by Polish Pharmaceutical Society. This is an access article under the CC BY NC license 